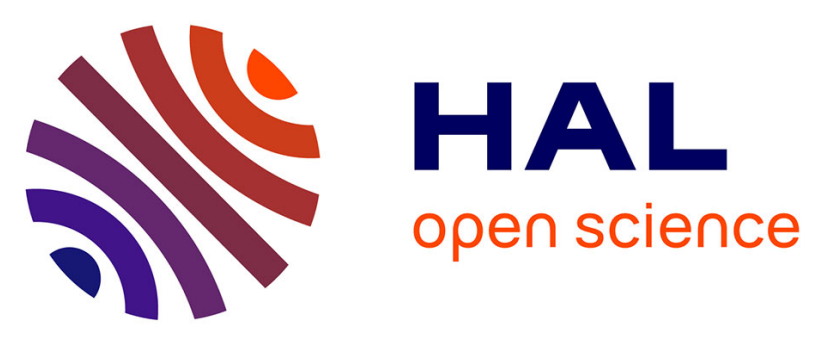

\title{
Numerical end experimental investigation of hygro mechanical states of glass fiber reinforced polyester composites experienced by FBG sensors
}

Hossein Ramezani Dana, Frédéric Jacquemin, Sylvain Fréour, Annick

Perronnet, Pascal Casari, Cyril Lupi

\section{To cite this version:}

Hossein Ramezani Dana, Frédéric Jacquemin, Sylvain Fréour, Annick Perronnet, Pascal Casari, et al.. Numerical end experimental investigation of hygro mechanical states of glass fiber reinforced polyester composites experienced by FBG sensors. Composite Structures, 2014, 116, pp.38-47. 10.1016/j.compstruct.2014.04.018 . hal-01154405

\section{HAL Id: hal-01154405 \\ https://hal.science/hal-01154405}

Submitted on 26 Nov 2017

HAL is a multi-disciplinary open access archive for the deposit and dissemination of scientific research documents, whether they are published or not. The documents may come from teaching and research institutions in France or abroad, or from public or private research centers.
L'archive ouverte pluridisciplinaire HAL, est destinée au dépôt et à la diffusion de documents scientifiques de niveau recherche, publiés ou non, émanant des établissements d'enseignement et de recherche français ou étrangers, des laboratoires publics ou privés. 


\title{
Numerical and experimental investigation of hygro mechanical states of glass fiber reinforced polyester composites experienced by FBG sensors
}

\author{
H. Ramezani Dana*, F. Jacquemin, S. Fréour, A. Perronnet, P. Casari, C. Lupi \\ Université de Nantes - Centrale de Nantes, Institut de Recherche en Génie Civil et Mécanique (UMR CNRS 6183), IUT de Saint-Nazaire, 58, rue Michel Ange - BP 420, \\ 44606 Saint-Nazaire, France
}

\begin{abstract}
This study is focused on the finite element analysis of the hygro-elastic stresses experienced by unidirectional composite structures instrumented by Fiber Bragg Grating (FBG) sensors. One of the significant advantages of this method is that by taking into account the complex geometry of elaborated specimen and their different constituents with heterogeneous hygroscopic and mechanical properties. In the first time, the obtained results were compared with the results obtained owing to an analytical solution deduced from the simplified concentric cylinders approach. This comparison allows us to evaluate the reliability of the concentric cylinders approach which cannot account for every aspects of the actual geometry of the studied samples. Besides the numerical results were compared to the experimental characterization of the mechanical states deduced from the Fiber Bragg Grating measurements.
\end{abstract}

\footnotetext{
Keywords:

Finite element method

Hygroscopic aging

Fiber Bragg Grating sensors

Organic matrix composite
} 


\section{Introduction}

Organic matrix composites are used in several engineering applications such as aerospace, marine, automobile, civil engineering and so on. Their application is in growth due to very good ratio of

stiffness to weight. Composite structures are often submitted to humid environments during their life time [1,2]. It has been reported that organic matrices absorb significant amounts of moisture when exposed to humid environment [3-6]. Absorbed water may induce harmful effects on organic matrix composites [7-11]. In fact, the constituents of composites structures exhibit heterogeneous coefficients of moisture expansion and maximum moisture absorption capacity. As a consequence, multi-scale in-depth mechanical states profiles rise during the hygroscopic loading of organic matrix composites. According to the literature, the resulting mechanical states can eventually induce damage [12-14]. Thus, the durability of polymer composites may be impaired by hygroscopic loads. Monitoring the internal mechanical states experienced by reinforced polymer during the transient part of the diffusion process would actually be relevant in the aim of understanding and eventually being able to predict the durability of structural parts.

Recently, Fiber Bragg Grating sensors have been used to achieve the measurement of strain, temperature and other quantities of engineering interest [15-20].FBG sensors have several advantages over conventional electrical and piezoelectric sensors, due to their capacity to investigate the internal mechanical states in the depth of composite specimen [21-23]. However, the presence of FBG sensors in the depth of a composite structure induces a stress field perturbation. Considerable efforts have been made by researchers in order to develop analytical models enabling to predict the mechanical states occurring during both the transient stage and the permanent regime of the moisture diffusion process of organic matrix composites submitted to hygro-mechanical loads [24-27]. In previous studies, the hygroscopic stress and strain experienced by unidirectional fiber-reinforced composites have been analyzed by considering the concept of concentric cylinders [28]. The authors have developed this approach to predict the transient hygroscopic stresses in composite structure. However the real geometry of complex specimen cannot be considered in the context of this simplified approach. Besides, reference [28] assumes that the moisture diffusion process obeys a one-dimensional Fick's law, when a 3D kinetics would better represent the physics.

In this study, a finite element approach has been proposed in order to simulate the hygro-elastic stresses experienced, during an aging test, by composite specimens instrumented by FBG sensors. This method allows to properly account for the actual geometry of the elaborated specimen as well as their different constituents. The main objective of the present work consists in demonstrating the reliability of the analytical model based on the concentric cylinders approximation by comparing with the finite element method. The results of these two numerical methods were compared to experimental results also. This specific point was achieved by an experimental investigation of both the time-dependent moisture uptake and the strain field in composite samples owing to FBG sensors. In the previous work [28] the authors used an analytical solution for hygro-elastic stresses in multi-layered cylinders, In the present work the authors used the finite element method to analyze a hygro-elastic stresses where precise sample size was used. It should be noted that also in the previous work a one-dimensional Fick's law (1D) was used to simulate the kinetics of moisture absorption, but in the recent study a three-dimensional Fick's law (3D) was applied in order to moisture diffusion and hygroscopic stress modeling. Finally in the recent study, the FEM numerical results compared and consequently validate with experimental results.

\section{Concentric cylinders approach}

In order to simulate the presence of an optical fiber inserted in an unidirectional composite (Fig. 1) and estimate the mechanical

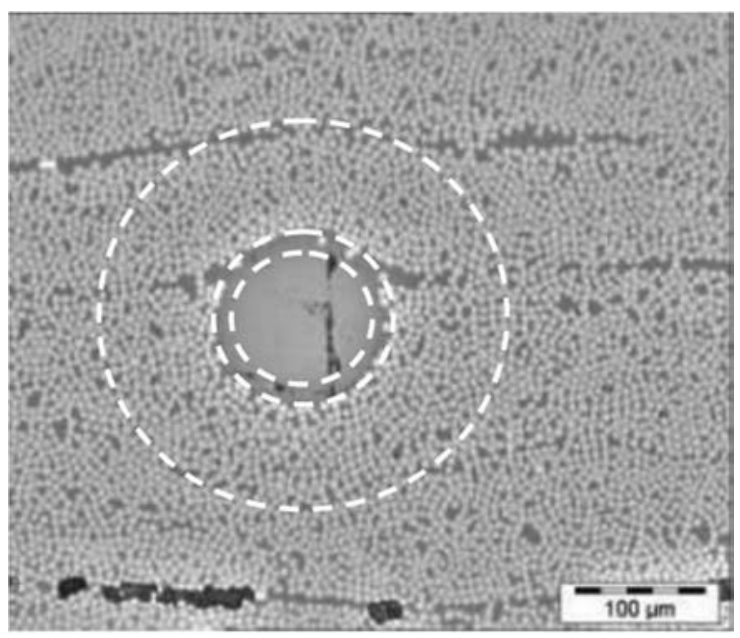

Fig. 1. Optical fibers inserted parallel to the reinforcing fibers (white dashed line circles illustrate, respectively the optical fiber, protective coating and unidirectional composite).

stress field experienced by the structure during an hygro-elastic load, a concentric cylinders model has been proposed in [28]. In this model, the hygro-elastic behavior of the central and the external cylinders were considered as isotropic and isotropic transverse, respectively. The optical fiber is surrounded by a protective coating considered as a third cylinder. This protective coating will be represented by an intermediate cylinder (Fig. 2) having isotropic properties. The radius of the optical fiber is $a$, whereas the outer radii of the protective coating and unidirectional composite are $r_{0}$ and $b$, respectively.

A list of symbols (Table 5) has been provided due to the large number of different symbols used in this paper.

\subsection{Hygroscopic problem}

The three cylinders are supposed initially dry. The moisture

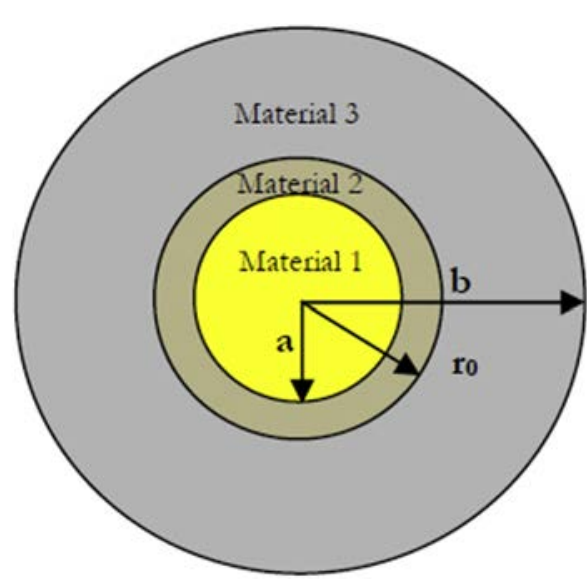

Fig. 2. Schema of the concentric cylinders model. 
coefficient in the ith cylinder and the external boundary moisture content, respectively. The moisture fluxes are continuous at the boundary between cylinders 2 and 3 , denoted, respectively by the subscripts 2 and 3 . A moisture content jump $(\alpha)$ is considered between cylinders 2 and 3 since both their densities and maximum moisture absorption capacities are heterogeneous [29]. This quantity $(\alpha)$ corresponds to the ratio of the maximum moisture absorption capacity of the second cylinder by that of the third cylinder (see system 2 below).

It is also assumed that moisture flow is zero at the interface between the cylinder 1 and cylinder 2 . This hypothesis is justified by the hydrophobic property of optical fiber represented by cylinder 1 .

$\frac{\partial m_{i}}{\partial t}=D_{(i)}\left[\frac{\partial^{2} m_{i}}{\partial r^{2}}+\frac{1}{r} \frac{\partial m_{i}}{\partial r}\right] \quad a<r<b, \quad t>0, \quad i=2$ to 3

$$
\left\{\begin{array}{l}
\frac{\partial m_{2}(a, t)}{\partial r}=0 \\
m_{2}\left(r_{0}, t\right)=\alpha m_{3}\left(r_{0}, t\right) \\
D_{(2)} \frac{\partial m_{2}\left(r_{0}, t\right)}{\partial r}=\boldsymbol{D}_{(3)} \frac{\partial m_{3}\left(r_{0}, t\right)}{\partial r} \\
m(b, t)=m_{0} \\
m_{i}(r, 0)=0
\end{array}\right.
$$

According to [30], the time and space dependant moisture content, $m_{2}(r, t)$, solution of the problem (1) and (2) is :

$$
\begin{aligned}
m(r, t)= & m_{0}\left[1+\pi \sum_{m=1}^{\infty} \frac{\exp \left(-D \omega_{m}^{2} t\right)}{J_{0}^{2}\left(b \omega_{m}\right)-J_{1}^{2}\left(a \omega_{m}\right)} J_{1}^{2}\left(a \omega_{m}\right)\left[Y_{0}\left(b \omega_{m}\right) J_{0}\left(r \omega_{m}\right)\right.\right. \\
& \left.\left.-J_{0}\left(b \omega_{m}\right) Y_{0}\left(r \omega_{m}\right)\right]\right]
\end{aligned}
$$

In order to solve the hygro-mechanical problem, the strain-displacement relations (5), as well as the compatibility and equilibrium Eq. (6) were considered [32]. By replacing the displacement components $(u, v, w)$ in the cylindrical coordinate system $(x, \theta, r)$, and employing the equilibrium equation we find the following relations

$\varepsilon_{33}=\frac{\partial w}{\partial r}, \quad \varepsilon_{22}=\frac{w}{r}, \quad \varepsilon_{11}=\frac{\partial u}{\partial x}$

$\frac{\partial \sigma_{33}}{\partial r}+\frac{\sigma_{33}-\sigma_{22}}{r}=0$

where $\varepsilon_{11}, \varepsilon_{22}, \varepsilon_{33}, \sigma_{11}, \sigma_{22}, \sigma_{33}$, are respectively the axial, hoop and radial strain and stress components.

The displacement $u(x)$ does not depend on the moisture content field. Additionally the radial component of the displacement $w(x)$ could be obtained by applying the solution of the analytical transient moisture content. (Eq. (3)).The radial component of the displacement field in the material 2 , denoted $w^{(2)}$, satisfies the following equation:

$\left\{\begin{array}{l}r^{2} \frac{\partial^{2} w^{(2)}}{\partial r^{2}}+r \frac{\partial w^{(2)}}{\partial r}-w^{(2)}=\frac{K_{1} r^{2} \frac{\partial \Delta m}{\partial r}}{L_{22}} \\ \text { with } K_{1}=L_{12} \beta_{11}+L_{23} \beta_{22}+L_{22} \beta_{22}\end{array}\right.$

Since the optical fiber is hydrophobic, the following simplified purely elastic relations (8) are considered for the displacement field which takes place within the cylinder $1[33,34]$.

$\left\{\begin{array}{l}u^{(1)}(x)=A^{(1)} x \\ w^{(1)}(r)=B^{(1)} r\end{array}\right.$

On the contrary, in the cylinders 2 and 3 which absorb water, the displacement fields write as follows (9):

$$
\left\{\begin{array}{l}
u^{(i)}(x)=A^{(i)} x \\
w^{(2)}(r)=B^{(2)} r+\frac{C^{(2)}}{r}+\sum_{m=1}^{\infty} \frac{m_{0} \pi \exp \left(-D \omega_{m}^{2} t\right)}{J_{0}^{2}\left(b \omega_{m}\right)-J_{1}^{2}\left(a \omega_{m}\right)} J_{1}^{2}\left(a \omega_{m}\right) \frac{K_{1}}{L_{22}} \\
{\left[Y_{0}\left(b \omega_{m}\right) \sum_{k=0}^{\infty} \frac{(-1)^{k}\left(\frac{1}{2}\right)^{2 k+1}\left(\omega_{m}\right)^{2 k+2}}{k !(k+1) !} \frac{r^{2 k+3}}{\left((2 k+3)^{2}-1\right)}-\frac{J_{0}\left(b \omega_{m}\right)}{\pi}\left[\sum_{k=0}^{\infty} \frac{(-1)^{k}\left(\frac{1}{2}\right)^{2 k+1}\left(\omega_{m}\right)^{2 k+2}}{k !(k+1) !}\left[2 \ln \left(\frac{1}{2} \omega_{m}\right)-\psi(k+1)-\psi(k+2)\right] \frac{r^{(2 k+3)}}{\left((2 k+3)^{2}-1\right)}\right.\right.} \\
\left.\left.\quad+2 \sum_{k=0}^{\infty} \frac{(-1)^{k}\left(\frac{1}{2}\right)^{2 k+1}\left(\omega_{m}\right)^{2 k+2}}{k !(k+1) !}\left[\frac{\ln (r) r^{2 k+3}}{\left((2 k+3)^{2}-1\right)}-\frac{2(2 k+3) r^{2 k+3}}{\left((2 k+3)^{2}-1\right)^{2}}\right]-r \ln (r)\right]\right]
\end{array}\right.
$$

With $\omega_{m}$ the $m$ th positive root of $J_{0}\left(b \omega_{m}\right) Y_{1}\left(a \omega_{m}\right)-J_{1}\left(a \omega_{m}\right)$ $Y_{0}\left(b \omega_{m}\right)=0$, where $J_{0}, J_{1}, Y_{0}$, and $Y_{1}$ are Bessel's functions of first or second kind.

Transient moisture concentration was determined also via the Finite difference method with an explicit formalism [31].

\subsection{Mechanical problem}

Initially, the cylinders are assumed to be stress free, so the hygro-elastic behavior (4) is written as follows:

$$
\left\{\begin{array}{l}
\sigma_{11} \\
\sigma_{22} \\
\sigma_{33}
\end{array}\right\}=\left[\begin{array}{lll}
L_{11} & L_{12} & L_{12} \\
L_{12} & L_{22} & L_{23} \\
L_{12} & L_{23} & L_{22}
\end{array}\right]\left\{\begin{array}{l}
\varepsilon_{11}-\beta_{11} \Delta m \\
\varepsilon_{22}-\beta_{22} \Delta m \\
\varepsilon_{33}-\beta_{22} \Delta m
\end{array}\right\}
$$

where $L$ and $\beta$, respectively stand for the elastic stiffness tensor and the coefficients of hygroscopic expansion. where $A^{(i)}, B^{(i)}, C^{(i)}$ are constants.

These unknown constants are deduced from the following conditions: continuity of the displacement components at the interface, continuity of the radial stress at the interface and stressfree condition at the outer radii, global force balance of the cylinder. The results obtained by this method will be presented in the Section 4.3.

\section{Finite element analysis}

In the above-described analytical model, the actual geometry of the instrumented specimen cannot fully be taken into account. Indeed, at the measurement point, where the Bragg grating is inscribed on the optical fiber, the acrylate protective coating was actually removed for the purpose of the experiments. This zone was thereafter filled by the polyester resin during the manufacturing process. Knowing that the length of the used Bragg grating is 


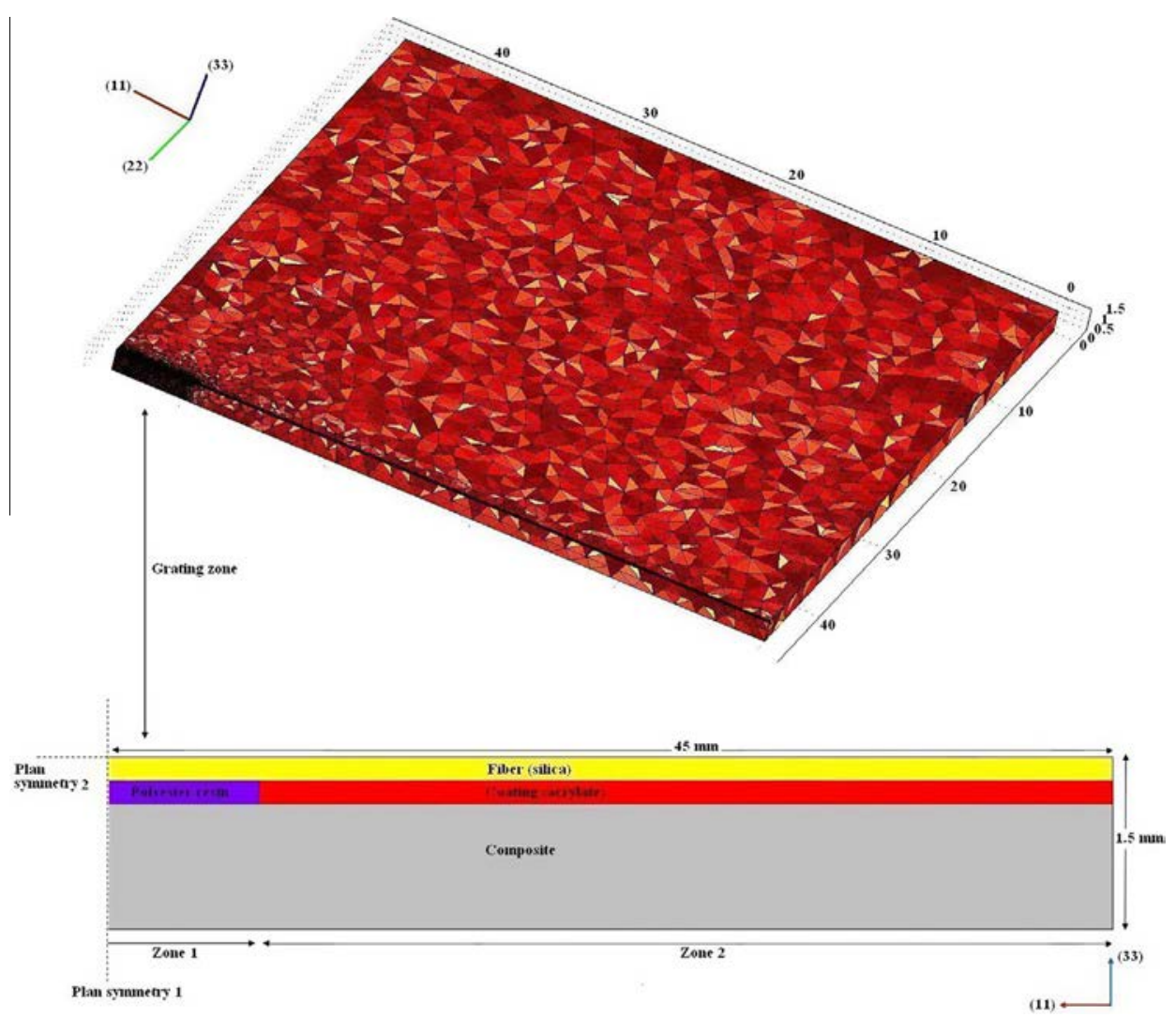

Fig. 3. Schematic view of the internal section of instrumented specimen.

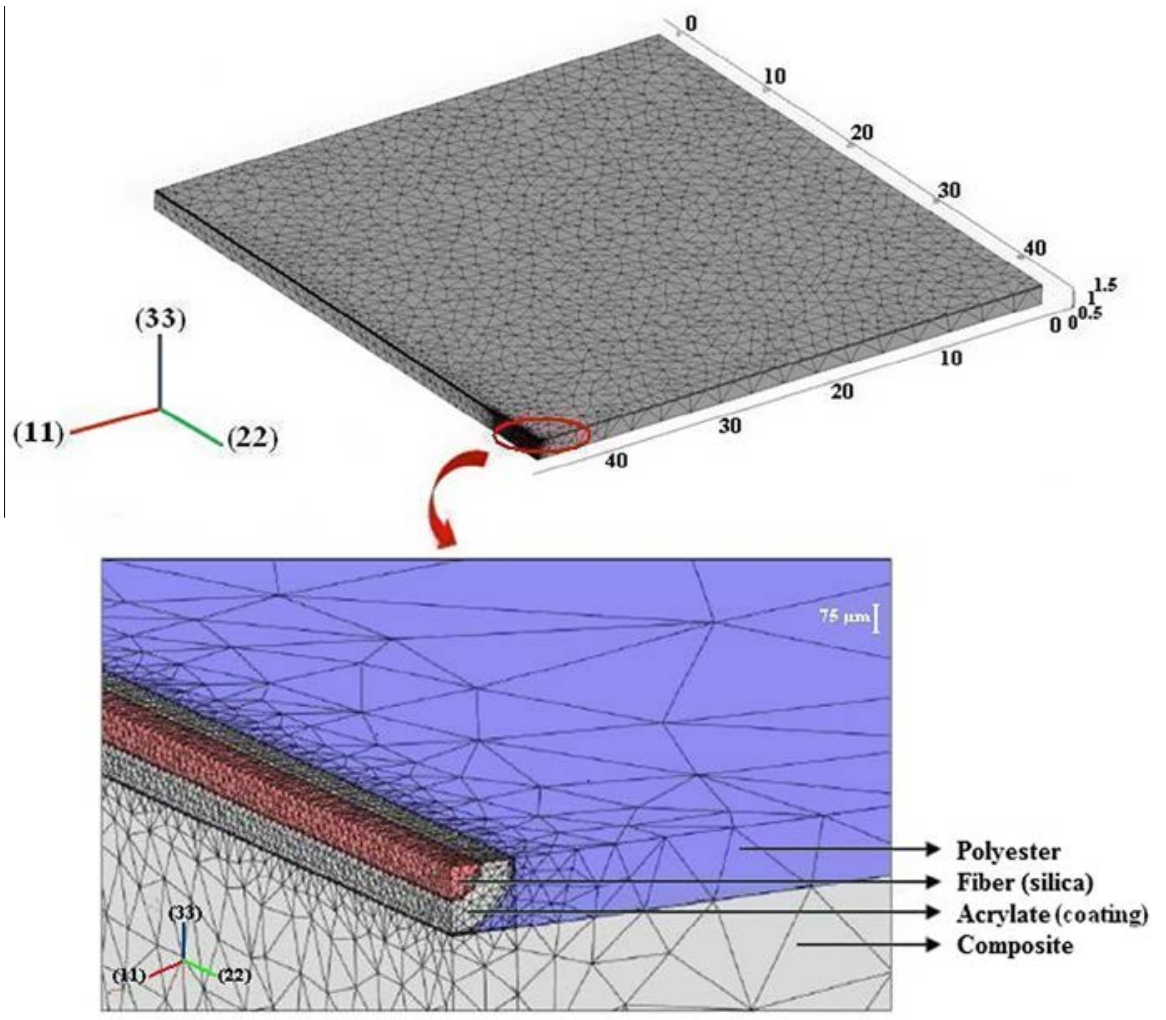

Fig. 4. Positioning of the FBG sensor in the elaborated sample with associated mesh refinement in the case when the FBG sensor positioned in the direction perpendicular to the reinforcement (considering with symmetry plane condition). 
$10 \mathrm{~mm}$, we can define two regions in the middle of the instrumented specimen. The first zone is constituted by the fiber embedded by the polyester resin and the composite. The length of this zone is $10 \mathrm{~mm}$. In the second zone the optical fiber is embedded by the acrylate coating instead of polyester resin. The length of the second zone is $80 \mathrm{~mm}$. (Fig. 3). In order to represent more realistically the instrumented samples, we used the finite element method to simulate the stress and strain evolution in the composite and the optical fiber. The results of these simulations will enable, to check the reliability of the approximations considered in the concentric cylinders approach.

\subsection{Size and shape of the specimen}

The tested unidirectional composite samples were made of Eglass fibers embedded in a polyester resin. The FBGs employed in this study were inscribed in standard optical fiber (SMF-28 e) the diameter of which is $250 \mu \mathrm{m}$. The optical fiber containing Bragg gratings was inserted between two composite plates bonded with polyester resin. The FBG were either aligned with the reinforcing fibers or set perpendicularly to them. These types of specimen architectures enabled us to obtain instrumented samples, the final size of which is $90 \times 90 \times 3 \mathrm{~mm}^{3}$. The optical fiber is surrounded by the composite plates considered as homogeneous equivalent materials. The main objective of this work consists in determining the moisture content evolution through the composite plate. Consecutively the strain and stress in the composite and the optical fiber induced by absorbed moisture will be predicted. For the purpose of the numerical simulations, in order to reduce the calculation time, three symmetry planes following the principal axis $\left(1^{\prime}, 2^{\prime}, 3^{\prime}\right)$ have been considered. This allows us to simplify the model by studying only one-eighth of the instrumented sample (Fig. 4). The sample size is reduced down to $45 \times 45 \times 1.5 \mathrm{~mm}^{3}$ by applying this simplification.

All FE simulations have been performed using the COMSOL Multiphysics ${ }^{\circledR}$ code. The mesh is constructed with tetrahedron elements and is refined at the fiber core near the Bragg grating, as well as at the fiber-matrix interface where the calculated fields may experience strong variations (Fig. 4).

Precisely our finite element model contains 126255 tetrahedron elements of degree 2 ( 9 nodes per element with quadratic shape function). A refined mesh was chosen in the specific zone where FBG sensor is inscribed. Additionally this area is particularly interesting for comparison with the experimental results obtained by optical Bragg grating sensor positioned in this point. In this zone the number of elements for the fiber (silica), acrylate coating, and composite plate are, respectively $18,108,48,905$, and 10,307. Besides, the moisture and mechanical fields in the rest of the specimens have been simulated with a less refined mesh in order to reduce the calculation time.

The following figure (Fig. 4) represent the positioning of the FBG sensor in the elaborated sample with associated mesh refinement in the case when the FBG sensor is positioned in the direction perpendicular to the reinforcement.

\subsection{Moisture diffusion and hygroscopic stress modeling}

The glass fiber reinforced polyester composite and the neat polyester resin samples exhibit a Fickien diffusive behavior as described in [35]. Accordingly, a three-dimensional Fick's law (10) was used to simulate the kinetics of water absorption:

$\frac{\partial c}{\partial t}=D_{1} \frac{\partial^{2} c}{\partial x^{2}}+D_{2} \frac{\partial^{2} c}{\partial y^{2}}+D_{3} \frac{\partial^{2} c}{\partial z^{2}}$

where $D_{1}, D_{2}$, and $D_{3}$ are diffusion coefficients longitudinal to the optical fibers, normal to the optical fibers but parallel to the composite plies and normal to both optical fibers and composite plies, respectively. The initials and boundaries conditions write as follow (11),

$$
c=c_{i} \text { for }\left\{\begin{array} { l } 
{ - \frac { L } { 2 } \leqslant x \leqslant \frac { L } { 2 } } \\
{ - \frac { l } { 2 } \leqslant y \leqslant \frac { l } { 2 } } \\
{ - \frac { e } { 2 } \leqslant z \leqslant \frac { e } { 2 } }
\end{array} \text { at } t = 0 \text { and } c = c _ { s } \text { for } \left\{\begin{array}{l}
x=-\frac{L}{2} ; x=\frac{L}{2} \\
y=-\frac{l}{2} ; y=\frac{l}{2} \\
z=-\frac{e}{2} ; z=\frac{e}{2}
\end{array} \text { at } t>0\right.\right.
$$

Subscripts $i$ and $s$ denote the moisture concentration values at the initial and permanent stages of the diffusion process, respectively. $L, l$, and $e$ are, respectively the length, the width and the thickness of the considered sample.

This method accounts for the moisture content jump existing at interface between the composite plate and the resin layer: actually, they present heterogeneous maximum moisture absorption capacities. In addition the diffusion flux is assumed to be continuous at this interface.

In order to simulate the hygroscopic stress induced by moisture diffusion, the hygro-elastic Hooke's law (12) has been used:

$$
\sigma=L:(\varepsilon-\beta \Delta C)
$$

The numerical model requires knowing the mechanical and hygroscopic properties of the various sample constituents, namely: the composite plate, the polyester resin layer, the acrylate protective coating and the fiber core (silica).

The hygroscopic properties of the unidirectional composite plate and the polyester resin layer, i.e. the maximum moisture content and the moisture diffusion coefficient values were, respectively measured and determined by using the gravimetric tests and identification methods described in previous study [36,37]. Besides, the values given in the literature $[38,39]$ were used for the acrylate protective coating. The mechanical properties provided by the supplier were used for the fiber core. Finally, some physical properties of the composite plate such as the moisture expansion coefficient have been determined experimentally via optical sensor, whereas its density was calculated from the rule of mixtures.

The mechanical and hygroscopic properties of the sample constituents are given in Tables 1 and 2 .

\section{Results and discussion}

\subsection{Transient moisture diffusion simulation}

The FBG sensors were positioned parallel and perpendicular to the reinforcing fibers in the elaborated samples. Thus, we simulate

Table 1

Hygroscopic properties of the sample constituents. properties.

\begin{tabular}{llllll}
\hline & $D_{11}\left(\mathrm{~mm}^{2} / \mathrm{s}\right)$ & $D_{22}\left(\mathrm{~mm}^{2} / \mathrm{s}\right)$ & $m_{\mathrm{s}}(\%)$ & $\beta_{11}$ & $\beta_{22}, \beta_{33}$ \\
\hline Composite $_{(17 \%)}$ & $2.31 * 10^{-7}$ & $2.07 * 10^{-7}$ & 0.85 & 0.021 & 0.471 \\
Composite $_{(21 \%)}$ & $2.31 * 10^{-7}$ & $1.74 * 10^{-7}$ & 0.78 & 0.026 & 0.398 \\
Composite $_{(22 \%)}$ & $2.31 * 10^{-7}$ & $1.97 * 10^{-7}$ & 0.79 & 0.042 & 0.397 \\
Resin & $2.31 * 10^{-7}$ & $2.31 * 10^{-7}$ & 1.51 & 0.346 & 0.346 \\
Acrylate coating & $5.64 * 10^{-7}$ & $5.64 * 10^{-7}$ & 3.11 & 0.5 & 0.5 \\
Fiber core & 0 & 0 & 0 & 0 & 0 \\
\hline
\end{tabular}

Table 2

Mechanical and physical properties of the sample constituents.

\begin{tabular}{lllll}
\hline & $E_{1}(\mathrm{GPa})$ & $E_{2} . E_{3}(\mathrm{GPa})$ & $v$ & $\rho\left(\mathrm{g} / \mathrm{cm}^{3}\right)$ \\
\hline Composite $_{(17 \%)}$ & 13.18 & 4.18 & - & 1.42 \\
Composite $_{(21 \%)}$ & 15.16 & 4.39 & - & 1.47 \\
Composite $_{(22 \%)}$ & 15.66 & 4.44 & - & 1.49 \\
Resin & 3.00 & 3.00 & 0.38 & 1.19 \\
Acrylate coating & 3.20 & 3.20 & 0.4 & 1.19 \\
Fiber core & 73.10 & 73.10 & 0.17 & 2.20 \\
\hline
\end{tabular}




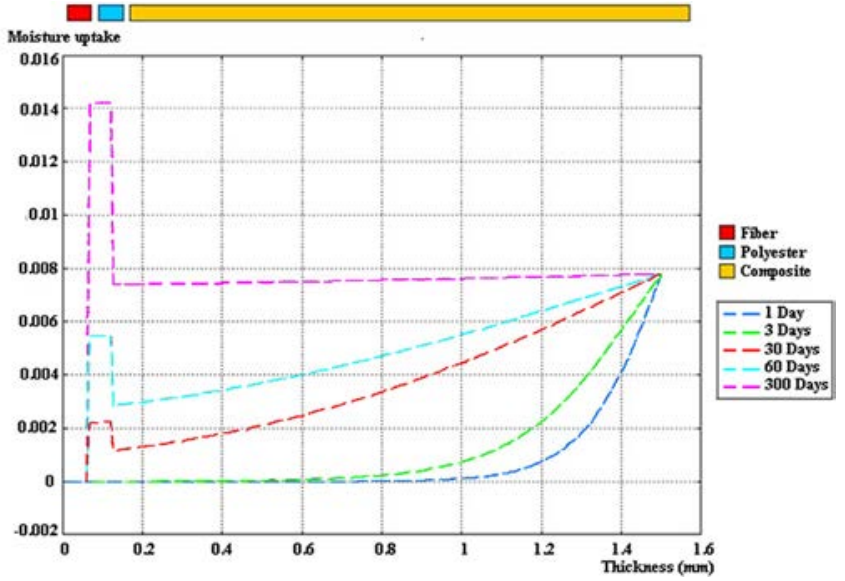

Fig. 5. Transient moisture uptake of composite sample with $22 \% v_{f}$.

hygro mechanical behavior of these samples in two principal directions. Fig. 5 depicts the transient moisture content of the specimen containing $22 \%$ glass fiber. The moisture content variation through the sample thickness, was plotted from point [(44.96, $44.985,0) \mathrm{mm}]$ to point $[(44.96,44.985,1.5) \mathrm{mm}]$. Three constituents with different moisture diffusion properties yield the existence of three zones with specific moisture uptakes in this direction (axis3').

It is found that the strongest gradient of moisture content occurs nearly to the sample edge. Then, the moisture diffuses through the whole composite cylinder, reducing the moisture content gradients (until the equilibrium state is finally attained). We can also observe a moisture uptake jump at polyester resin - composite interface due to their heterogeneous hygroscopic properties. The ratio between the maximum moisture content of the resin and composite plate allows us to determine the precise value of the moisture uptake jump named $\varsigma$. As an example $\varsigma$ is equal to 1.92 for the elaborated sample with $22 \% v_{f}$. The saturation of this specimen is attained within less than one year (300 days).

\subsection{Hygroscopic strain simulation}

Figs. 6(a)-(c) illustrate the radial, hoop and axial strains in the optical fiber, polyester resin layer and composite plate, calculated during the transient stage, in the case when FBG sensor is positioned parallel to the reinforcing fibers. On these figures, the strain/stress values are interpolated via the shape function regarding to the nodes. The radial strain is discontinuous at the interface between the composite plate and the polyester resin layer, where the moisture content jump occurs. The radial strain reaches $3500 * 10^{-6}, 11,000 * 10^{-6}$, and $400 * 10^{-6}$ in the composite plate, polyester resin layer and optical fiber, respectively at equilibrium state. The radial strains predicted for any of the three constituents, according to this method are reasonable, regarding to their moisture uptake.

Contrary to the case of the radial strain, a fairly uniform hoop strain is experienced by the composite plate during the moisture diffusion process. The hoop strain is more important in the composite than in the optical fiber.
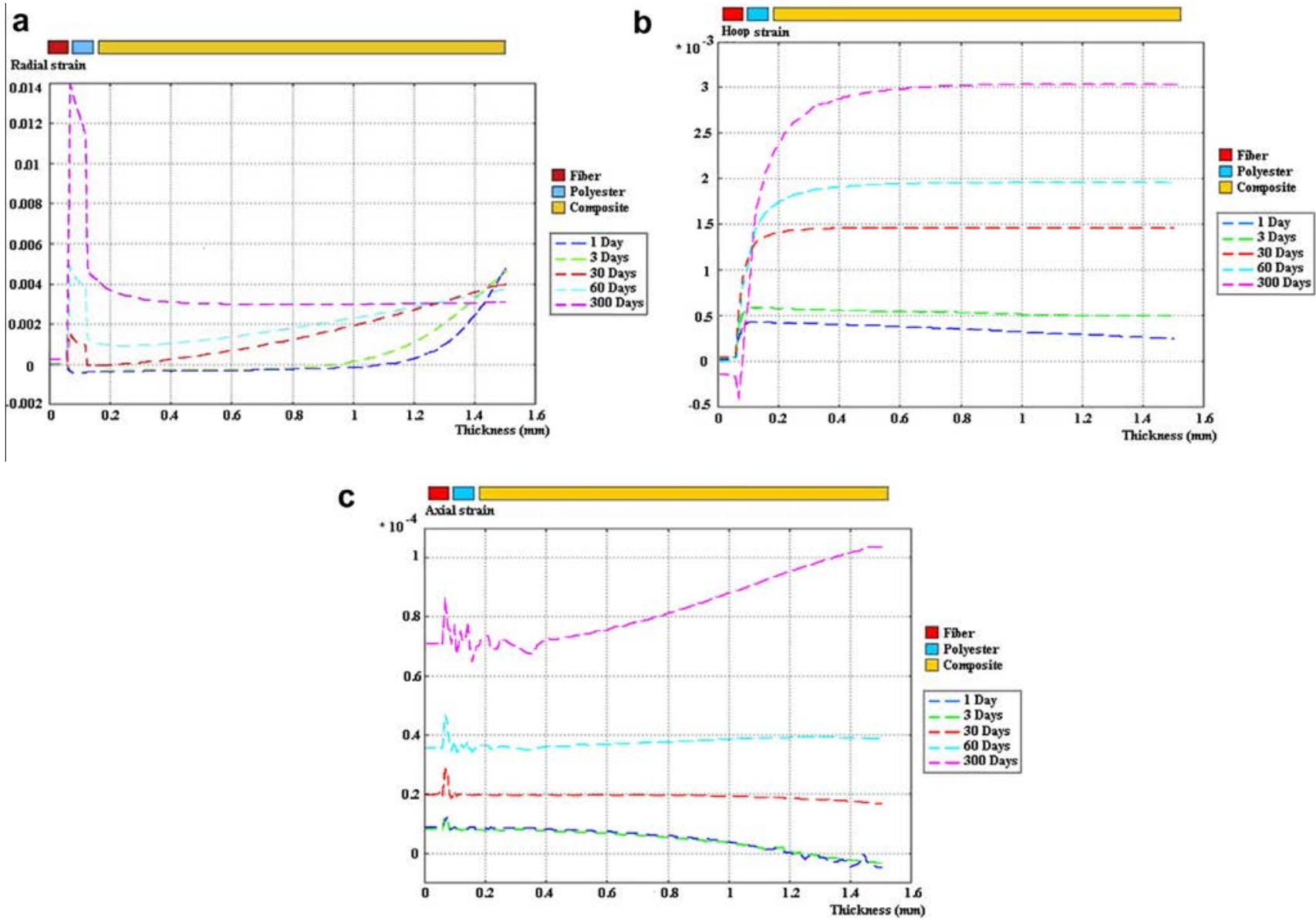

Fig. 6. Radial, hoop and axial strain in transient state for instrumented simple, where FBG is positioned parallel to the reinforcing fibers. 


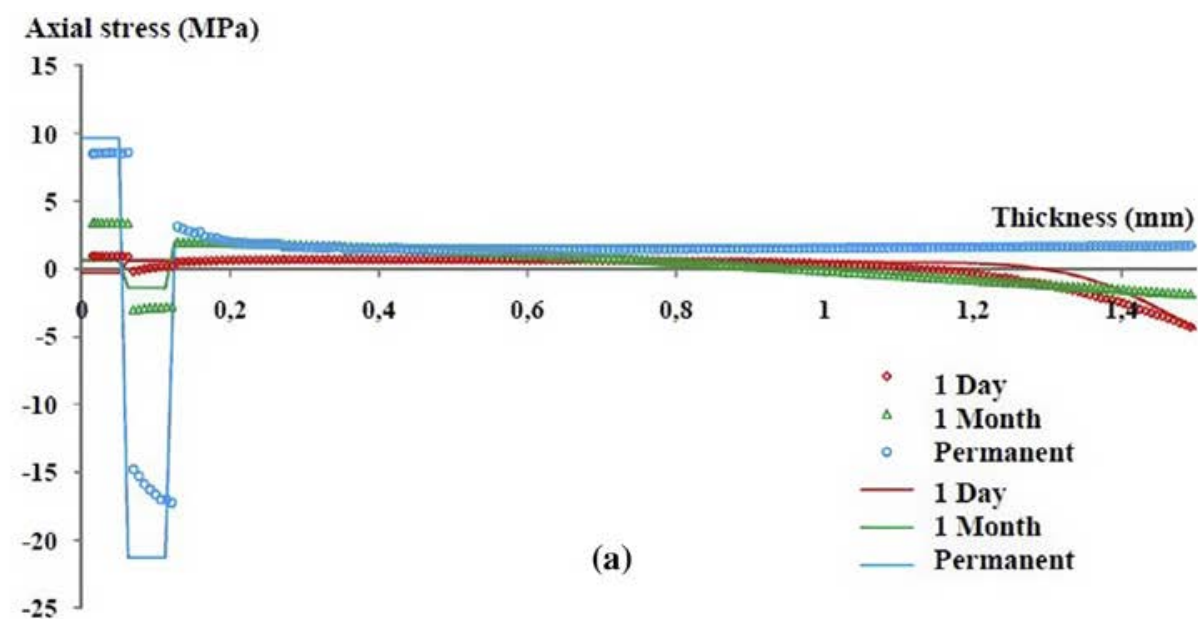

Hoop stress ( MPa)
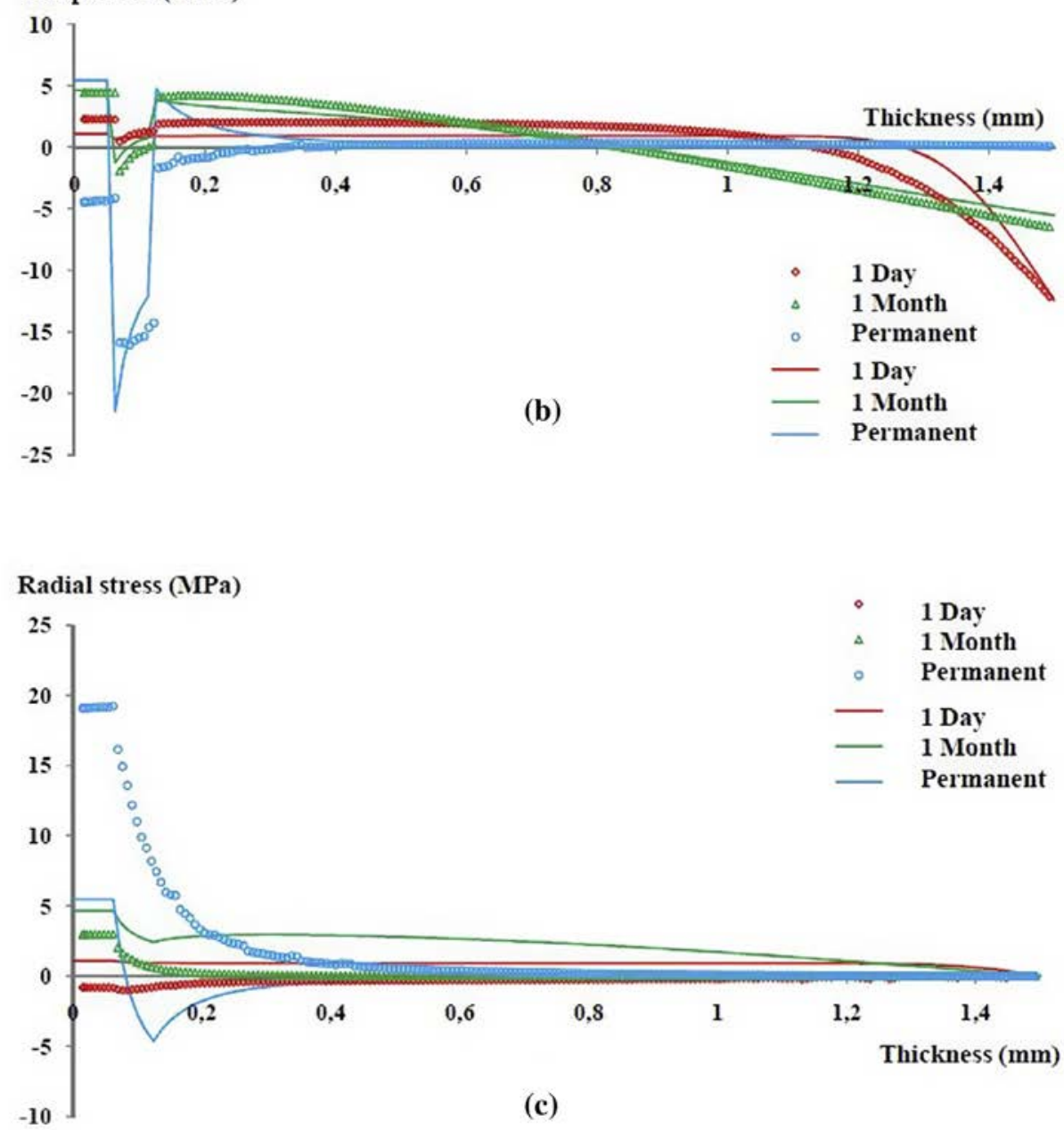

Fig. 7. Axial, hoop and radial stress in transient state obtained by finite element method (dots) and the analytical approach (lines), in the case when FBG sensor is positioned parallel to the reinforcing fibers.

The axial strain represents the hygroscopic deformation along the reinforcing fibers. In fact in this direction the hygroscopic strain is small, $\left(70 * 10^{-6}\right)$ due to the hydrophobic properties of glass fibers, as well as their high stiffness in that specific direction. This effect has been illustrated by Fig. 6(c). Actually, the axial strain is nearly constant in the composite plate and the fiber core (silica). On the contrary a tiny fluctuation was observed for the axial strain experienced by the polyester resin layer because of its hydrophilic properties. Globally the axial strain at saturation state (after 300 days) is negligible in comparison with radial and hoop strain. 
4.3. Numerical comparison of hygroscopic stress with FE results and concentric cylinder results

The importance of the performed simulation is that the actual geometry of the instrumented sample and the constituents distribution has properly been taken into account during FE analysis, whereas the concentric cylinder method is based upon approximations. In order to evaluate the influence of this factor on the hygro mechanical states, the radial, hoop and axial stress predicted by finite element method and calculated by concentric cylinder approach, have been compared.

Fig. 7 represents the axial, hoop and radial stress in transient state obtained by both the theoretical approaches. This figure corresponds to the case of a sample with $22 \%$ of reinforcing fibers. In addition the FBG sensor was considered parallel to the reinforcing fibers.

The two methods are consistent on many aspects: as an example, compressive stress gradients for both hoop and axial stresses are predicted near to the external surface in the transient stage. Strong discontinuities of the hoop and axial stresses can be observed at the boundaries between the interphase material, the optical fiber and the composite.

The computations show that the maximum tensile hoop and axial stresses are reached during the diffusion process in the composite subdomains. High radial stress gradients which increase as a function of the time take place in the resin region (Fig. 7(c)) according to both the calculation methods.

Globally, the axial and hoop stress results obtained by both methods in the composite, resin and optical fiber subdomains are consistent. On the opposite, the radial stress obtained by the two methods present significant discrepancies, as high as $13 \mathrm{MPa}$, particularly in the optical fiber subdomains. This could be explained by the main assumptions involved in the concentric cylinder model.

In fact the FE method takes into account the actual structure of instrumented sample, precisely in the vicinity of the optical fiber where Bragg grating is inscribed. Notably at this measurement point, the acrylate protective coating was removed. This zone has been filled by the polyester resin during the manufacturing process. Knowing that the moisture diffusion, and consequently, the moisture uptake, are dissimilar for these two materials, can constitute an explanation for the discrepancy with the calculated hygroscopic strains.

Since the maximum moisture capacity of the acrylate coating is two times higher than that of the polyester resin (3.1\% against $1.5 \%$ [39]), we could expect the hygroscopic strain experienced by the acrylate to be higher than that of the polyester. The acrylate coating is placed between the composite plate and optical fiber core. This induces a different strain profile through the thickness of the instrumented sample, where we observe a compression state for the polyester resin layer (Fig. 3).

This modification of the hygro-mechanical state in the core of sample in the vicinity of FBG sensor, due to the presence of an acrylate coating with different hygroscopic property, is not taken into account by the concentric cylinder approach.

\subsection{Comparison with experimental results}

\subsubsection{Hygroscopic strain measurement by FBG sensors}

Hygroscopic strains have been measured by FBG sensors inserted in composite plates in order to validate the obtained numerical results. The FBG sensors were positioned perpendicular and parallel to the reinforcing fibers in order to provide information in both the principal directions. The samples were intended to provide the time-dependent evolution of the internal strains states throughout the moisture diffusion process. They were eventually immersed in de-ionized water at the beginning of the aging tests.

Mechanical strains measurements through FBG have been presented in various papers [40]. A FBG consists in a series of grating planes formed along the fiber axis. If the Bragg condition is fulfilled, a light signal propagating into the device can interfere constructively to the waves reflected by each of the grating planes. As a result, a back reflected signal with a center wavelength commonly known as the Bragg wavelength $\lambda_{b}$ is formed. In the case when the FBG is submitted to a homogeneous axial strain $\varepsilon_{z}$ and uniform temperature change $\Delta T$, the Bragg wavelength experiences a deviation $\Delta \lambda_{b}$ from the reference value $\lambda b_{0}$ corresponding to the unloaded state $\left(\varepsilon_{z}=0 ; \Delta T=0\right)$ :

$\frac{\Delta \lambda_{b}}{\lambda_{b}}=\frac{\lambda_{b}-\lambda_{b 0}}{\lambda_{b}}=a \varepsilon_{z}+b \Delta T$

Coefficients $a$ and $b$ depend on the nature of the optical fiber and the FBG inscription parameters. According to relation (13), at isothermal conditions, the Bragg wavelength shift $\Delta \lambda_{b}$ is proportional to the axial strain experienced by the optical fiber.

The measured Bragg's wavelength shift enables to determine the strain experienced in the center of the instrumented samples, from relation (13), provided that the thermal contribution, namely, the product $b . \Delta T$ is negligible by comparison to the quantity of interest: $a \cdot \varepsilon_{z}$

\subsubsection{Experimental set up and data exploitation}

A broadband optical source provided by pumping an erbiumdoped fiber, has been used in this experimental set up. The source spectral width is about $30 \mathrm{~nm}$ centered at $1550 \mathrm{~nm}(1550 \mathrm{~nm} \pm$ $30 \mathrm{~nm}$ ). The FBGs were inscribed in the standard SMF-28e single mode optical fiber of $250 \mu \mathrm{m}$ diameter via phase mask method. The Bragg grating length is $10 \mathrm{~mm}$. The reflected signal is received back by a JDS Uniphase coupler $(1 * 2)$. The reflected signal is processed by a spectrum analyzer (Anritsu MS9710B) with $70 \mathrm{pm}$ graphic resolution.

The coupler actually guides the reflected signal to the Spectrum Analyzer. The spectral signature of the Bragg grating is numerically analyzed in order to determine the measured strain during the hygroscopic aging test imposed to the samples.

Besides, the hygroscopic properties of the composite and the pure polyester resin samples have been determined owing to the gravimetric test. In particular, the maximum water uptake, was deduced from those measurements. This makes it possible to plot the curve of the hygroscopic strain as a function of the water uptake. From this curve the coefficients of moisture expansion of the studied samples can be determined. The values of these coefficients are presented in Table 3.

According to the obtained results, the strain value and consequently the moisture expansion coefficient of specimens is higher in the direction perpendicular to the reinforcing fibers. In fact the moisture expansion coefficient in the direction parallel to the reinforcement fiber weakly depends to the fiber volume fraction $\left(v_{f}\right)$. Knowing that the fiber volume fraction difference for these composites is about $1 \%$, the low difference in beta $11\left(\beta_{11}\right)$ is conceivable. Accordingly the measured value in that direction is of the same order of magnitude than the uncertainty.

Table 3

Coefficients of Moisture Expansion.

\begin{tabular}{llllll}
\hline$v_{f}(\%)$ & $m_{s}(\%)$ & $\varepsilon_{11}\left(10^{-6}\right)$ & $\varepsilon_{22}\left(10^{-6}\right)$ & $\beta_{11}$ & $\beta_{22}$ \\
\hline 17 & 0.85 & 180 & 4000 & 0.022 & 0.472 \\
21 & 0.79 & 330 & 3140 & 0.042 & 0.397 \\
22 & 0.78 & 200 & 3100 & 0.026 & 0.397 \\
\hline
\end{tabular}


Table 4

Comparison between the results predicted by finite element simulation and the Fiber Bragg Grating sensor measurement for elaborated composite with $22 \%$ fiber volume fraction.

\begin{tabular}{lll}
\hline & FE Simulation prediction & FBG sensor measurement \\
\hline Axial $\left(\varepsilon_{11}\right)$ & $100 * 10^{-6}$ & $239 * 10^{-6}$ \\
Hoop $\left(\varepsilon_{22}\right)$ & $3600 * 10^{-6}$ & $3480 * 10^{-6}$ \\
Radial $\left(\varepsilon_{33}\right)$ & $500 * 10^{-6}$ & \\
\hline
\end{tabular}

This should obviously be attributed to the strongly anisotropic hygroscopic behavior of fiber-reinforced composites [41].

\subsubsection{The experimental and numerical results confrontation}

The data collected through the experimental tests; in particular, the measured hygroscopic strains, were confronted with the numerical results in order to validate the applied numerical approach. It should be remembered that the FBG sensors were initially positioned either parallel or perpendicular to the reinforcing fibers. As a result, the experimental investigation provides both the axial and circumferential strains in the transient state in the immediate vicinity of the sensors. However, the mechanical strain was not investigated in the direction normal to the fibers of the composite plies due to the very small sample thickness (less than $3 \mathrm{~mm}$ ). Therefore the confrontation of the numerical approaches with the experimental method is not possible in the direction normal to the fibers of the composite plies. This is due to the lack of experimental reference values in this direction. Actually, the two predictive approaches used in the present work predict significantly different levels of stress in the direction normal to the fibers, as evidenced by the analysis described in Section 4.3.

However, a very good agreement between the theoretical predictions and the measured profiles was eventually found in the others principal directions. Knowing that the FE method takes into account the actual geometry of the instrumented specimen and the spatial distribution of its constituent, particularly in the vicinity of the FBG sensor, we utilized the hygroscopic strains simulated by this method for this comparison. It should be noted that the measured circumferential strains were applied for this comparison and the FBG sensor was considered perpendicular to the reinforcing fibers.

At the saturation state, the FBG sensor measured the value of $3484 * 10^{-6}$ for hoop strain which is very close to the value of
$3600 * 10^{-6}$ predicted by the FE simulations. The relative deviation in this case reduces to $3.3 \%$. Several factors, particularly the uncertainty of the measurement could explain this small discrepancy. This comparison justifies also the reliability of the materials parameters employed in the constitutive hygro-elastic equation, for the needs of the FE simulation.

The results obtained by these simulations have been grouped in Table 4.

\section{Conclusions}

This study is devoted to the hygro-elastic behavior of unidirectional composite structures. The investigation was achieved through measurements and numerical computations. Internal strains states in the longitudinal and transverse directions to the reinforcing fibers were determined owing to Fiber Bragg Grating sensors, during the transient stage of aging tests (immersion in de-ionized water).

The moisture content distribution through the instrumented sample thickness was computed as a function of time owing to Finite Element Method. The heterogeneous diffusion coefficients and maximum moisture absorption capacities of the various constituents of the studied specimen were accounted for. The local strain and stress fields in the composite structure have been calculated by the same approach. The influence of an interphase, here the polyester resins subdomain between two unidirectional composite plates, and the existence of an acrylate protective coating between the fiber core (silica) and the composite plates have been commented. The results obtained by the Finite Element Model were compared to the values predicted by a simplified analytical solution established owing to the concentric cylinder method.

A very good agreement between the two computational approaches shows the reliability of the concentric cylinder method. Finally the hygro-mechanical properties of elaborated sample have been measured via FBG sensors in order to validate the obtained numerical results. Good agreement of experimental results and numerical results represents the adjustment of $\mathrm{FE}$ method to predict the hygro-mechanical state of elaborated specimens. In addition, it attests the reliability of the parameters used in the constitutive hygro-elastic equation, during the FE simulation.

The FE method was used in order to simulate the hygro-elastic behavior of unidirectional composite structures only in the present

Table 5

A list of symbols used in this paper.

\begin{tabular}{|c|c|c|c|}
\hline Symbol & Meaning & Symbol & Meaning \\
\hline$D_{(i)}$ & The transverse diffusion coefficient in the $i$ th cylinder & $c$ & The Moisture concentration \\
\hline$D_{(2)}$ & The transverse diffusion coefficient in the 2 th cylinder & $D_{1}$ & Longitudinal diffusion coefficient \\
\hline$D_{(3)}$ & The transverse diffusion coefficient in the 3th cylinder & $D_{2}, D_{3}$ & Transverse diffusion coefficient \\
\hline$m_{i}$ & The moisture content in the ith cylinder & $c_{i}$ & The initial moisture concentration. \\
\hline$m_{2}$ & The moisture content in the 2 cylinder & $c_{s}$ & The maximum equilibrium Moisture concentration. \\
\hline$m_{3}$ & The moisture content in the 3 cylinder & $L, l, e$ & The length, the width, and the thickness of the considered sample. \\
\hline$\alpha$ & $\begin{array}{l}\text { The moisture content jump between cylinder } 2 \text { and } 3 \text { (in concentric } \\
\text { cylinder approach) }\end{array}$ & $E_{1}$ & Longitudinal elastic modulus \\
\hline$m(r, t)$ & The time and space dependent moisture content & $E_{2}, E_{3}$ & Transverse elastic modulus \\
\hline$\omega_{m}$ & The $\mathrm{m}^{\text {ième }}$ positive root of $: J_{0}\left(b \omega_{m}\right) Y_{1}\left(a \omega_{m}\right)-J_{1}\left(a \omega_{m}\right) Y_{0}\left(b \omega_{m}\right)=0$ & $v$ & Poisson's ratio \\
\hline $\begin{array}{l}J_{0}, J_{1}, Y_{0} \& \\
\quad Y_{1}\end{array}$ & Bessel's functions of first or second kind & $\rho$ & Density \\
\hline$\sigma_{11}$ & Axial stress & $v_{f}$ & Fiber volume fraction \\
\hline$\sigma_{22}$ & Hoop stress & $\varepsilon_{z}$ & Axial strain in cylindrical coordinate \\
\hline$\sigma_{33}$ & Radial stress & $\varsigma$ & $\begin{array}{l}\text { The moisture uptake jump at polyester resin - composite interface (in } \\
\text { finite element method) }\end{array}$ \\
\hline$\varepsilon_{11}$ & Axial strain & $m_{s}$ & The maximum equilibrium Moisture content. \\
\hline$\varepsilon_{22}$ & Hoop strain & $U(X)$ & Axial component of displacement \\
\hline$\varepsilon_{33}$ & Radial strain & $W(X)$ & Radial component of displacement \\
\hline$\beta_{11}$ & Axial coefficient of hygroscopic expansion & $u^{(i)}(x)$ & Axial component of displacement in the $i$ th cylinder \\
\hline$\beta_{22}$ & Radial coefficient of hygroscopic expansion & $w^{(i)}(r)$ & Radial component of displacement in the $i$ th cylinder \\
\hline
\end{tabular}


study. Such a method could be developed in order to simulate the hygro-elastic behavior of cross-ply composite laminate.

\section{References}

[1] Jedidi J, Jacquemin F, Vautrin A. Design of accelerated hygrothermal cycles on polymer matrix composites in the case of a supersonic aircraft. Compos Struct 2005;68:429-37.

[2] Helbling C, Abanilla M, Lee L, Karbhari VM. Issues of variability and durability under synergistic exposure conditions related to advanced polymer composites in the civil infrastructure. Compos A 2005;37:1102-10.

[3] Springer GS. Environmental effects on composites material. Westport, Connecticut: Technomic Publishing Co.; 1984.

[4] Shen CH, Springer GS. Moisture absorption and desorption of composite materials. J Compos Mater 1976;10:2-20.

[5] Weitsman YJ. Effects of fluids on polymeric composites - a review. In: Manson JAE, Talreja R, editors. Comprehensive materials, polymeric matrix composites. Amsterdam: Elsevier; 2000. p. 369-401.

[6] Bao LR, Yee AF. Effect of temperature on moisture absorption in bismaleimide resin and its carbon fiber composites. Polymer 2002;43:3987-97.

[7] Baschek G, Hartwig G, Zahradnik F. Effect of water absorption in polymers at low and high temperatures. Polymer 1999;40:3433-41.

[8] Selzer R, Friedrich K. Mechanical properties and failure behavior of carbon fibers-reinforced polymer composites under the influence of moisture. Composite Part A 1976;28:595-604.

[9] Berry NG, Almeida JRM, Barcia FL, Soares BG. Effect of water absorption on the thermal-mechanical properties of HTPB modified DGEBA-based epoxy systems. Polym Test 2007;26:262-7.

[10] Zafar A, Bertocco F, Schjdt-Thomsen J, Rauhe JC. Investigation of the long term effects of moisture on carbon fibre and epoxy matrix composites. Compos Sci Technol 2012;72:656-66.

[11] Faguaga E, Pérez CJ, Villarreal N, Rodriguez ES, Alvarez V. Effect of water absorption on the dynamic mechanical properties of composites used for windmill blades. Mater Des 2012;36:609-16.

[12] Perreux D, Suri C. A study of the coupling between the phenomena of water, absorption and damage in glass/epoxy composite pipes. Compos Sci Techno 1997;57:1403-13.

[13] Chiou P, Bradley WL. Effects of seawater absorption on fatigue crack developments in carbon/epoxy EDT specimens. Composites 1995;26:869-76.

[14] Weitsman YJ, Elahi M. Effects of fluids on the deformation, strength and durability of polymeric composites - an overview. Mech Time Dependent Mater 2000;4:107-26.

[15] Colpo F, Humbert H, Botsis J. Characterisation of residual stresses in a single fibre composite with FBG sensor. Compos Sci Technol 2007;67:1830-41.

[16] Mihailov SJ. Fiber Bragg grating sensors for harsh environments. Sensors 2012;12(2):1898-918

[17] Eric U. Review of multi-parameter fiber grating sensors. In: Fiber Optic Sensors and Applications V, Proceedings of the (SPIE), Boston, September 2007.

[18] Karalekas D, Cugnoni J, Botsis J. Monitoring of hygrothermal ageing effects in an epoxy resin using FBG sensor: a methodological study. Compos Sci Techno 2009;69:507-14.

[19] Bosia F, Botsis J, Facchini M, Giaccari P. Deformation characteristics of composite laminates-part I: speckle interferometry and embedded Bragg grating sensor measurements. Compos Sci Technol 2002;62(1):41-54.

[20] Mulle M, Collombet F, Olivier P, Zitoune R, Huchette C, Laurin F, et at Assessment of cure-residual strains through the thickness of carbon-epoxy laminates using FBGs Part II: technological specimen. Compos A Appl Sci Manuf 2009;40(10):1534-44.
[21] Giaccari P, Dunkel GR, Humbert L, Botsis J, Limberger HG, Salathé RP. On a direct determination of non-uniform internal strain fields using fibre Bragg grating. Smart Mater Struct 2005;14(1):127-36.

[22] Frieden J, Cugnoni J, Botsis J, Gmür T. High-speed internal strain measurements in composite structures under dynamic load using embedded FBG sensors. Compos Struct 2010;92(8):1905-12.

[23] Papantoniou A, Rigas G, Alexopoulos ND. Assessment of the strain monitoring reliability of fiber Bragg grating sensor (FBGs) in advanced composite structures. Compos Struct 2011;93:2163-72.

[24] Marom G, Broutman LJ. Moisture penetration into composites under external stress. Polym Compos 1981;2(3):132-6.

[25] Neumann S, Marom G. Free-volume dependent moisture diffusion under stress in composite materials. J Mater Sci 1986;21:26-30.

[26] Yaniv G, Ishai O. Coupling between stresses and moisture diffusion in polymeric adhesives. Polym Eng Sci 1987;27(10):731-9.

[27] Sar BE, Fréour S, Davies P, Jacquemin F. Coupling moisture diffusion and internal mechanical states in polymers - a thermodynamical approach. Eur J Mech A Solids 2012;36:38-43.

[28] Jacquemin F, Fréour S, Guillén R. Analytical modeling of transient hygro-elastic stress concentration - application to embedded optical fiber in a non-uniform transient strain field. Compos Sci Technol 2006;66:397-406.

[29] Youssef G, Fréour S, Jacquemin F. Stress-dependent moisture diffusion in composite materials. J Compos Mater 2009;43(15):1621-37.

[30] Crank J. The mathematics of diffusion. 2nd ed. Oxford Clarendon Press; 1967.

[31] Patankar SV. Numerical heat transfer and fluid flow. Hemisphere Publishing Corporation; 1980.

[32] Jacquemin F, Vautrin A. Modeling of the moisture concentration field due to cyclical hygrothermal conditions in thick laminated pipes. Eur J Mech A Solids 2002;21:845-55.

[33] Anifantis NK, Kakavas PA, Papanicolaou GC. Thermal stress concentration due to imperfect adhesion in fiber-reinforced composites. Compos Sci Technol 1997;57:687-96.

[34] Wagner HD, Nairn JA Residual thermal stresses in three concentric transversely isotropic cylinders: application to thermoplastic-matrix composites containing a transcrystalline inter-phase. Compos Sci Technol 1997;57:1289-302.

[35] Ramezani Dana H, Casari P, Perronnet A, Fréour S, Jacquemin F, Lupi C. Internal strain measurement of glass-polyester composites under hygro-thermal ageing test using fiber Bragg gratings. In: Proceeding of 15th European conference on composite materials (ECCM/15), Venice, Italy, 2012.

[36] Ramezani Dana H, Perronnet A, Fréour S, Casari P, Jacquemin F. Identification of moisture diffusion parameters in organic matrix composites. J Compos Mater 2013;47(9):1081-92.

[37] Ramezani Dana H, Casari P, Perronnet A, Fréour S, Jacquemin F, Lupi C, et al, Hygroscopic strain measurement by fibre Bragg gratings sensors in organic matrix composites - application to monitoring of a composite structure. Compos B 2014:58:76-82.

[38] Smith KE, Trusty P, Wan B, Gall K. Long-term toughness of photopolymerizable (meth)acrylate networks in aqueous environments. Acta Biomater 2011;7:558-67.

[39] Unemoria M, Matsuyaa Y, Matsuyab S, Akashia A, Akamine A. Water absorption of poly(methyl methacrylate) containing 4-methacryloxyethyl trimellitic anhydride. Biomaterials 2003;24:1381-7.

[40] Botsis J, Humbert L, Giaccari P. Embedded fiber Bragg grating sensor for internal strain measurements in polymeric materials. Opt Lasers Eng 2005;43:491-510.

[41] Jacquemin F, Fréour S, Guillén R. A hygroelastic self-consistent model for fiberreinforced composites. J Reinf Plast Compos 2005;24:485-502. 